\title{
Invasive behavior of ulcerative colitis-associated carcinoma is related to reduced expression of CD44 extracellular domain: comparison with sporadic colon carcinoma
}

\author{
Tetuo Mikamii, Tsutomu Yoshida, Yoshiko Numata, Masaomi Kikuchi, Kayo Araki, Norihiro Nakada and \\ Isao Okayasu
}

\begin{abstract}
Background: To elucidate relations of invasion of ulcerative colitis (UC)-associated carcinoma with its prognosis, the characteristics of invasive fronts were analyzed in comparison with sporadic colonic carcinomas.

Methods: Prognoses of 15 cases of UC-associated colonic carcinoma were compared with those of sporadic colon carcinoma cases, after which 75 cases of sporadic invasive adenocarcinoma were collected. Tumor budding was examined histologically at invasive fronts using immunohistochemistry $(\mathrm{IHC})$ of pancytokeratin. Expressions of betacatenin with mutation analysis, CD44 extracellular domain, Zo-1, occludin, matrix matalloproteinase-7, laminin-5 $\gamma 2$, and sialyl Lewis $X\left(L^{X}\right)$ were immunohistochemically evaluated.

Results: UC-associated carcinoma showed worse prognosis than sporadic colon carcinoma in all the cases, and exhibited a tendency to become more poorly differentiated when carcinoma invaded the submucosa or deeper layers than sporadic carcinoma. When the lesions were compared with sporadic carcinomas considering differentiation grade, reduced expression of CD44 extracellular domain in UC-associated carcinoma was apparent. Laminin-5y2 and sialyl-Le expression showed a lower tendency in UC-associated carcinomas than in their sporadic counterparts. There were no differences in the numbers of tumor budding foci between the two lesion types, with no apparent relation to nuclear beta-catenin levels in IHC.

Conclusions: UC-associated carcinoma showed poorer differentiation when the carcinoma invaded submucosa or deeper parts, which may influence the poorer prognosis. The invasive behavior of UC-associated carcinoma is more associated with CD44 cleavage than with basement membrane disruption or sialyl-Lewis-antigen alteration.
\end{abstract}

\section{Background}

It is certain that patients with ulcerative colitis (UC) are more liable to develop a colon carcinoma than those without UC [1]. In our experience, UC-associated carcinoma tends to be more poorly differentiated when the carcinoma invades deeper than the submucosa, even if it is well differentiated in the lamina propria. Although the prognosis of UC-associated carcinoma had been regarded as grave in the past [2,3], clinicopathological studies suggested similarity to sporadic colorectal

\footnotetext{
* Correspondence: mikamit@med.kitasato-u.ac.jp

* Correspondence: mikamit@med.kitasato-u.ac.jp
Department of Pathology, Kitasato University School of Medicine Sagamihara, Japan
}

(c) 2011 Mikami et al; licensee BioMed Central Ltd. This is an Open Access article distributed under the terms of the Creative Commons Attribution License (http://creativecommons.org/licenses/by/2.0), which permits unrestricted use, distribution, and reproduction in any medium, provided the original work is properly cited. noma and sporadic colon carcinoma has not yet been elucidated.

Focusing on factors for invasion, we earlier compared expression of cell adhesion molecules in UC-associated carcinomas with those in sporadic colonic adenocarcinomas, revealed significantly decreased expressions of CD44 and alpha-catenin and altered expression of betacatenin in UC-associated lesions [5]. However, it was unclear whether or not UC-associated carcinoma has a more invasive behavior and whether or not carcinoma cell differentiation influences the biological behavior in the difference of invasion between UC-associated and 
UC-associated lesions. Therefore, in the present study, we tried to compare UC-associated carcinoma cases with sporadic colorectal adenocarcinoma counterparts, focusing on prognosis, tumor cell differentiation, tumor budding, and several protein expressions.

Recently, tumor budding has become considered a major malignant characteristic of colorectal carcinomas $[6,7]$. Defined as the presence of isolated single cells or small cell clusters ( $\leq 4$ cells) scattered in the stroma at invasive fronts [6], this features loss of both glandular differentiation and cell cohesion that is crucial for the development of high-invasive properties. Tumor budding has been reported to be a risk factor for lymphatic involvement and lymph node metastasis in sporadic colorectal carcinomas [8,9]. However, the prognoses of patients with UC-associated carcinomas are not known.

Regarding cell adhesion molecules, the down-regulation of CD44 expression is reported to correlate with metastasis and poor prognosis in various types of carcinoma $[10,11]$. Recently, it was reported that CD44 reduction is caused in part by the proteolysis-based cleavage of its extracellular domain, which occurs in many malignant tumors [12]. Zo-1 and occludin are tight junction-associated proteins, which seal the cells together and prevent diffusion of solutes from the outside [13]. It was reported that both occludin and Zo-1 showed reduced expression in poorly differentiated gastrointestinal carcinoma [13].

When beta-catenin translocates into the nucleus and binds to the T-cell factor, it acts as a transcription factor for various genes [14], including matrix metalloproteinase-7 (MMP-7, matrilysin) [15], which is known to play roles in extracellular matrix degradation $[16,17]$. One of the main targets of MMP-7 in epithelial basement membranes is the laminin-5 isoform, formed by association of $\alpha 3, \beta 3$, and $\gamma 2$ chains. Specific cleavage of the laminin-5 $\gamma 2$ chain by members of the MMP family has been proposed to favor cell migration $[17,18]$.

A modified blood group ABO/Lewis antigen, sialyl Lewis $\mathrm{X}\left(\mathrm{Le}^{\mathrm{X}}\right)$ is present on the surfaces of human leukocytes $[19,20]$. It was also reported to be expressed in colonic carcinoma cells while sialyl 6 -sulfo $\mathrm{Le}^{\mathrm{X}}$ is characteristic of normal colonic epithelium [21], and it was considered to play an important role in metastasis through the binding to E-selectin on endothelial cells [22]. Increased expression of sialyl $\mathrm{Le}^{\mathrm{X}}$ correlates with a poor prognosis in patients with colorectal carcinoma, demonstrating relations to the depth of tumor invasion, lymph node metastasis, lymphatic invasion, and the disease stage [23,24].

In the present study, expression of CD44 extracellular domain, Zo-1, occludin, MMP-7, and laminin-5 2 in association with beta-catenin nuclear localization, and levels of sialyl $\mathrm{Le}^{\mathrm{X}}$ were immunohistochemically investigated along with tumor budding in UC-associated and sporadic colon carcinomas, with the aim of elucidating differences in mechanisms of invasion and biological behavior between the two types of colon carcinomas in relation to prognoses.

\section{Methods}

From the pathology files of Kitasato University East Hospital and three other affiliated hospitals, 15 cases of UC-associated colonic carcinoma were collected, and 12 of those 15 were located in the left hemicolon. Histologically, 6 cases were well differentiated adenocarcinoma, 4 cases being moderately differentiated adenocarcinoma, and 5 cases being poorly differentiated adenocarcinoma (including signet ring cell carcinoma). Duration of illness from onset to surgical resection was from 6 to 19 years (mean, 13.1 years). The lesions were histologically confirmed by three expert pathologists (TM, TY, and IO) according to the criteria of Riddell et al. [25].

\section{Prognosis analysis}

A total of 300 consecutive cases of sporadic advanced adenocarcinoma were collected from the pathology files of the Kitasato University East Hospital from 1999 to 2000. The prognosis data of 15 UC-associated adenocarcinomas, and these 300 sporadic adenocarcinoma cases, were examined from their clinical charts. When calculating overall survival in the present study, only deaths from carcinoma were considered in the analysis.

\section{Histopathological examination}

As sporadic counterparts, sporadic invasive adenocarcinoma cases of 5 times the number of UC-associated lesion cases were collected for the two histologic groups: 30 cases of well differentiated and 45 cases of moderately to poorly differentiated adenocarcinoma (moderately differentiated, 37 cases; poorly differentiated, 8 cases). The lesions were histologically confirmed by three pathologists (TM, TY, and IO), according to the World Health Organization histological typing [26]. In order to guarantee the material quality for immunohistochemical reaction and DNA analysis, the additional 75 cases from 2003 to 2004 were collected, not including the above 300 cases.

All histopathological materials were fixed in $10 \%$ buffered formalin and routinely processed for embedding in paraffin. From the invasive carcinoma lesions, both UCassociated and sporadic, paraffin blocks, including the deepest invasion parts, were chosen for examination. The differentiation of adenocarcinoma at both the surface and deep parts were histologically examined for each lesion.

Immunohistochemical staining of 4-micrometer-thick paraffin sections was performed using a commercial kit 
(EnVision+, Dako, Glostrup, Denmark). The primary antibodies used and methods for antigen retrieval are listed in Table 1. Microwave oven heating (500 W, $5 \mathrm{~min}, \times 3$ times) was done with a target retrieval solution (pH 9.0, Dako) for cytokeratin, and with a target retrieval solution ( $\mathrm{pH}$ 6.0, Dako) for MMP-7, beta-catenin, laminin-5 2 , and sialyl $\mathrm{Le}^{\mathrm{X}}$ to retrieve antigenic activity. Protease treatment $\left(15 \mathrm{~min}, 37^{\circ} \mathrm{C}\right)$ was done for $\mathrm{Zo}-1$ and occludin. The sections were subsequently incubated with the primary antibodies at $4^{\circ} \mathrm{C}$ overnight. After processing according to the manufacturer's protocols, 3,3'-diaminobenzidine was used as the final chromogen, and nuclei were counter-stained with hematoxylin or methyl green.

\section{Evaluation of tumor budding}

Isolated single carcinoma cells and small cell clusters composed of fewer than five carcinoma cells were defined as tumor budding foci in the stroma at actively invasive tumor margins [6]. The numbers of tumor budding foci on pancytokeratin-stained slides were counted using a $\times 10$ objective lens along the invasive front of carcinomas for at least $1.5 \mathrm{~cm}$ in length per case, after which the value per $1 \mathrm{~cm}$ was calculated.

Expression of CD44 extracellular domain, MMP-7, laminin$5 \gamma 2$, sialyl Le ${ }^{\mathrm{X}}$, Zo-1, occludin, and beta-catenin

At the invasive fronts of carcinoma lesions, immunoreactivity for CD44 extracellular domain, MMP-7, laminin-5 $\gamma 2$, and sialyl $\mathrm{Le}^{\mathrm{X}}$ was evaluated and semiquantified according to the classification of Sinicrope et al. [27] focusing on both staining intensity and frequency of stained cells. The intensity was scored: weak, 1; moderate, 2; intense, 3. For frequency, positive cells were expressed as the percentage of the total number of cells in the invasive front and assigned to 1 of 5 categories: $0,<5 \%$; $1,6-25 \%$; 2, 26-50\%; 3, 51-75\%; 4, >76\%. Immunoreactivity scores for each lesion were calculated by multiplication of the values for the two parameters. For Zo-1 and occludin staining, the expression was observed at the cell surface of the lumen composed of adenocarcinoma cells. The expression pattern, linear or dot-like, was investigated. For beta-catenin, when more than $20 \%$ of the carcinoma cells showed nuclear immunoreactivity [28], the case was judged as nuclear betacatenin positive (Table 1). Sinicrope's method, described above, was used for the beta-catenin membranous and cytoplasmic expressions [27].

\section{DNA extraction and sequencing analysis}

DNA was extracted from formalin-fixed, paraffinembedded tissue samples. Five $10-\mu$ m-thick sections were cut and deparaffinized in xylene before dehydration with $100 \%$ ethanol. After nuclear staining with hematoxylin, lesions were microdissected under a microscope with disposable scalpels, and DNA was extracted with an extraction kit (QIAamp DNA Mini Kit, Qiagen, Hilden, Germany). The collected samples were treated with proteinase $\mathrm{K}$, and lysates were processed according to the manufacturer's protocols.

Examination of the exon 3 sequence of the betacatenin gene was done according to the methods used

Table 1 Antibodies used for the immunohistochemical examination

\begin{tabular}{|c|c|c|c|c|c|}
\hline Antibody & Clone & Source & Dilution & Antigen retrieval & Interpretation \\
\hline $\begin{array}{l}\text { CD44 extracellular } \\
\text { domain } \\
\text { (aminoterminal end) }\end{array}$ & $\begin{array}{l}\text { Polyclonal, } \\
\text { Ab64929 }\end{array}$ & $\begin{array}{l}\text { Abcam, Cambridge, } \\
\text { MA }\end{array}$ & $1 / 50$ & Not applied & Sinicrope's method* \\
\hline Zo-1 & $\begin{array}{l}\text { Polyclonal, } \\
61-7300\end{array}$ & $\begin{array}{l}\text { Zymed, South San } \\
\text { Francisco, CA }\end{array}$ & $1 / 100$ & Protease treatment $\left(15 \mathrm{~min}, 37^{\circ} \mathrm{C}\right)$ & Linear or dot-like \\
\hline Occludin & $\begin{array}{l}\text { Polyclonal, } \\
71-1500\end{array}$ & Zymed & $1 / 100$ & Protease treatment $\left(15 \mathrm{~min}, 37^{\circ} \mathrm{C}\right)$ & Linear or dot-like \\
\hline MMP-7 & $\begin{array}{l}\text { Monoclonal, } \\
\text { 141-7B2 }\end{array}$ & $\begin{array}{l}\text { Daiichi Fine } \\
\text { Chemical, Takaoka, } \\
\text { Japan }\end{array}$ & $1 / 200$ & $\begin{array}{l}\text { Microwave treatment for } 15 \mathrm{~min} \\
\text { (Dako target retrieval solution } \\
{[\mathrm{pH} 6.0] \text { ) }}\end{array}$ & Sinicrope's method* \\
\hline Pancytokeratin & $\begin{array}{l}\text { Monoclonal, } \\
\text { MNF116 }\end{array}$ & $\begin{array}{l}\text { Dakocytomation, } \\
\text { Glostrup, Denmark }\end{array}$ & $1 / 50$ & $\begin{array}{l}\text { Microwave treatment for } 15 \mathrm{~min} \\
\text { (Dako target retrieval solution } \\
\text { [pH 9.0]) }\end{array}$ & For evaluation of tumor budding \\
\hline beta-Catenin & $\begin{array}{l}\text { Monoclonal, } \\
\text { 14/beta- } \\
\text { catenin }\end{array}$ & $\begin{array}{l}\text { BD Transduction } \\
\text { laboratories, } \\
\text { Lexington, KY }\end{array}$ & $1 / 200$ & $\begin{array}{l}\text { Microwave treatment for } 15 \mathrm{~min} \\
\text { (Dako target retrieval solution } \\
\text { [pH 6.0]) }\end{array}$ & $\begin{array}{l}\text { Nuclear, more than } 20 \% \text { judged as positive; } \\
\text { membranous and cytoplasmic, Sinicrope's } \\
\text { method* }\end{array}$ \\
\hline Laminin-5 $\gamma 2$ & $\begin{array}{l}\text { Monoclonal, } \\
4 \mathrm{G} 1\end{array}$ & Dakocytomation & $1 / 50$ & $\begin{array}{l}\text { Microwave treatment for } 15 \mathrm{~min} \\
\text { (Dako target retrieval solution } \\
{[\mathrm{pH} \mathrm{6.0])}}\end{array}$ & Sinicrope's method* \\
\hline Sialyl Lewis X & $\begin{array}{l}\text { Monoclonal, } \\
\mathrm{FH} 6\end{array}$ & $\begin{array}{l}\text { Ohtsuka } \\
\text { Pharmaceutical, } \\
\text { Tokushima, Japan }\end{array}$ & $1 / 2000$ & $\begin{array}{l}\text { Microwave treatment for } 15 \mathrm{~min} \\
\text { (Dako target retrieval solution } \\
\text { [pH 6.0]) }\end{array}$ & Sinicrope's method* \\
\hline
\end{tabular}


by Saegusa et al. [29]. Briefly, amplification was achieved by polymerase chain reaction (PCR) using TaKaRa ExTaq polymerase (Takara Bio Inc., Ohtsu, Japan) in a volume of $20 \mu \mathrm{l}$ with forward (5'-ATTTGATGGAGTTGGACATGG-3') and reverse (5'-TCTTCCTCA GGATTGCCTT-3') primers with the conditions: 33 cycles of $94^{\circ} \mathrm{C}$ for $0.5 \mathrm{~min}, 55^{\circ} \mathrm{C}$ for $1 \mathrm{~min}$, and $72^{\circ} \mathrm{C}$ for $1 \mathrm{~min}$. Subsequently, $5 \mu \mathrm{l}$ aliquots of reaction products were applied to agarose gel electrophoresis to confirm the PCR reaction. As a negative control, water was supplied instead of template DNA for each examination.

The remaining $15 \mathrm{ml}$ aliquots of $\mathrm{PCR}$ products were purified using a QIAquick PCR Purification Kit (Qiagen) and sequenced using a BigDye Terminator Cycle Sequencing Kit (Applied Biosystems, Foster City, CA) according to the manufacturers' protocols. The DNA sequence data were collected and analyzed on an ABI Prism 3100 automated DNA sequencer (Applied Biosystems). If a mutation was found using the forward PCR primer, the reverse PCR primer was used to confirm the mutation.

\section{Statistical analysis}

Statistical analysis was performed using the $\chi^{2}$ and Mann-Whitney $U$ tests. When more than 3 groups were compared, the Kruskal Wallis test with the Mann-Whitney $U$ test was applied. Prognosis was analyzed by the Kaplan-Meier method with the log-rank test. All calculations were performed using SPSS computer software (SPSS Inc., Chicago, IL, USA), and $P$-values less than 0.05 were considered statistically significant.

\section{Results}

Prognosis was analyzed for Stage 2 and 3 cases (9 UCassociated and 244 sporadic carcinomas). As for overall survival of all cases, UC-associated carcinoma showed worse prognosis than sporadic carcinoma $(P=0.010)$ (Figure 1). However, when the cases were limited to well differentiated carcinomas, no significant difference was shown $(P=0.136)$. Similarly, the cases limited to moderately to poorly differentiated ones, no significant difference was shown $(P=0.071)$. Clinicopathological data for the $15 \mathrm{UC}$-associated and 75 sporadic colon carcinoma cases are summarized in Table 2. There were no differences in the rates of lymph node metastasis between the 2 groups (Table 2). In comparison between the surface and deep parts of the lesions, UC-associated carcinomas tended to become more poorly differentiated when the carcinoma invaded the submucosa or deeper (Table 3). The rate of the cases which showed poorer differentiation at the deep part was significantly higher in UC-associated carcinoma (10 of 15 cases, 66.7\%) than in sporadic colon carcinoma (25 of 75 cases, $33.3 \%)(P=0.033)$.

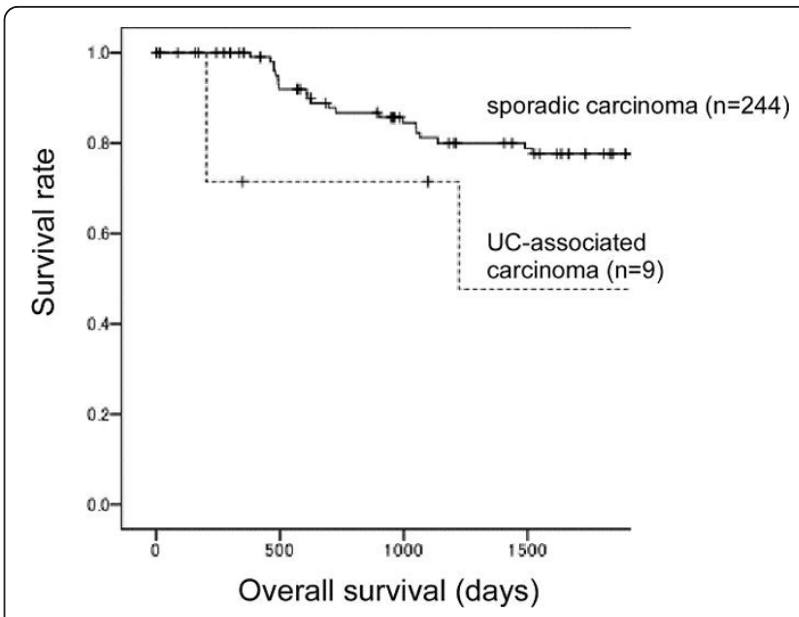

Figure 1 Prognoses were analyzed for cases of ulcerative colitis (UC)associated and sporadic colon carcinomas of stages

2 and 3. For all cases, UC-associated carcinoma showed worse overall survival than sporadic carcinoma $(P=0.010)$. When cases were limited to well differentiated carcinomas, no significant difference was shown $(P=0.136)$. Similarly, the cases limited to moderately to poorly differentiated ones, no significant difference was shown $(P=0.071)$.

The lesions were divided according to their differentiation, and UC-associated and sporadic carcinomas were compared in each differentiation category. CD44 extracellular domain showed lower expression in UCassociated carcinoma than in sporadic carcinoma, in both the well-differentiated category and the poorly differentiated category $(P=0.010, P<0.001$, respectively) (Figure 2) in invasive fronts. As the colon carcinoma cases would generally be divided into two categories: well to moderately differentiated and poorly differentiated cases [26], comparison between the 2 categories revealed that CD44 extracellular domain expression was significantly higher in sporadic well to moderately differentiated carcinoma than in the UC-associated counterparts $(P=0.002)$. There were no differences in tumor budding and MMP-7 expression. Laminin-5 2 and sialyl $\mathrm{Le}^{\mathrm{X}}$ both showed higher expression in sporadic carcinomas than in their UC-associated counterparts, without statistical significance (Table 4) (Figure 3). In division into the 2 categories, sialyl-Le ${ }^{\mathrm{X}}$ expression was significantly higher in sporadic well to moderately differentiated carcinoma than in their UC-associated counterparts $(P=0.016)$.

Expression of both Zo-1 and occludin was observed as lines or dots on the apical cell surface of a lumen or cell adhesion site. At the invasive fronts of UC-associated carcinoma of the 6 cases of well differentiated carcinoma, Zo-1 and occludin were expressed as a line pattern in $5(83.3 \%)$ and a dot pattern in 1 (16.7\%), respectively; and of the 9 cases of moderately to poorly 
Table 2 Clinicopathological summary of the cases

\begin{tabular}{llll}
\hline & $\begin{array}{l}\text { UC- } \\
\text { associated }\end{array}$ & $\begin{array}{l}\text { Sporadic } \\
\text { value }\end{array}$ \\
\hline Site & 12 & 41 & 0.068 \\
$\quad \begin{array}{l}\text { Left side } \\
\text { Right side }\end{array}$ & 3 & 34 & \\
Histological type & & & \\
$\quad$ Well differentiated & 6 & 30 & \\
$\quad$ Moderately differentiated & 4 & 37 & \\
$\quad \begin{array}{l}\text { Poorly differentiated (including } \\
\text { signet-ring cell carcinoma) }\end{array}$ & 5 & 8 & \\
Depth of invasion & & & \\
$\quad$ Up to MP & & & \\
SS/A or deeper & 2 & 12 & 0.79 \\
Lymph node metastasis & 13 & 63 & \\
Negative & & & \\
Positive & 5 & 31 & 0.56 \\
Stage & 10 & 44 & \\
I & & & \\
II & 2 & 9 & 0.14 \\
III & 3 & 22 & \\
IV & 9 & 44 & \\
\hline
\end{tabular}

UC-ulcerative colitis; MP-muscularis propria; SS-subserosa; A-adventitia.

differentiated carcinoma were expressed as a line pattern in $5(55.6 \%)$ and a dot pattern in $4(44.4 \%)$. On the other hand, all $30(100 \%)$ well differentiated sporadic lesions showed linear expression of Zo-1 and occludin. For the 45 moderately to poorly differentiated cases, 36 (80.0\%) showed a linear expression and 9 (20.0\%) showed a dot pattern expression (Figure 2). There were no significant differences between UC-associated and sporadic carcinomas.

There were no differences in numbers of tumor budding foci among the sporadic carcinomas of the right and left hemicolon and the UC-associated carcinomas (Table 5). In addition, there were no differences in tumor budding between nuclear beta-catenin negative and positive cases of sporadic carcinoma. Cytoplasmic beta-catenin expression was significantly stronger in nuclear positive than in nuclear negative cases of sporadic carcinoma (Table 6) (Figure 4). In the UC-associated carcinomas, 1 of 2 nuclear beta-catenin positive lesions was a signet-ring cell carcinoma mixed with mucinous carcinomas. Therefore, comparison between nuclear beta-catenin negative and positive lesions in UC-associated carcinoma was not considered appropriate.

Mutations in beta-catenin exon 3 were found in 1 of $32(3.1 \%)$ sporadic carcinomas of the right and 1 of 41 $(2.4 \%)$ of the left hemicolon, but none were found in the 7 cases of UC-associated carcinomas examined. PCR or sequencing reactions failed in 11 cases, probably due to the poor quality of the extracted DNA.

\section{Discussion}

In the present study, for overall cases, the prognosis of UC-associated carcinoma was worse than that of sporadic colon carcinoma. However, significant difference was not shown when the cases were limited to the same tumor differentiation. Because the UC-associated carcinoma cases contained much poorly differentiated cases, and since the number of cases was small, it was difficult to conclude that the prognosis of UC-associated carcinoma is definitely worse than that of its sporadic counterpart. However, the character that UC-associated carcinoma showed poorer differentiation at the invasion area in the submucosa or deeper parts may influence the prognosis.

The frequency of beta-catenin gene mutation was low in both UC-associated and sporadic carcinomas. In the literature, the frequency in sporadic colorectal carcinoma has varied from the $0 \%$ reported by Garinis et al. [30] to the percentages of $22 \%$ and $26 \%$, respectively, described by Mirabelli-Primdahl et al. [31] and Aust et al. [32]. In contrast, Aust et al. [32] found no betacatenin mutations in UC-associated carcinomas. Garinis

Table 3 Comparison of histologic type between mucosa and deeper parts (submucosa or deeper) of cancer lesion

\begin{tabular}{|c|c|c|c|c|}
\hline & & $\begin{array}{l}\text { UC-associated } \\
(n=15)\end{array}$ & $\begin{array}{l}\text { Sporadic } \\
(n=75)\end{array}$ & $P$ value \\
\hline Mucosa area & Deeper area & & & \\
\hline Well & Well & 2 & 25 & \\
\hline Well & Moderately & 5 & 18 & \\
\hline Well & Poorly & 2 & 0 & \\
\hline Moderately & Moderately & 1 & 20 & \\
\hline Moderately & Poorly & 3 & 7 & \\
\hline Poorly & Poorly & 2 & 5 & $0.0062^{*}$ \\
\hline Poorer differentiation in deep parts** & & $10(66.7 \%)$ & $25(33.3 \%)$ & $0.033^{*}$ \\
\hline
\end{tabular}

UC - ulcerative colitis; $n$ - number of cases.

* $\chi^{2}$ test.

** Cases which were shown to be well differentiated at the mucosa and moderately to poorly differentiated at the deep areas, and showed moderately differentiated at mucosa and poorly differentiated at the deep areas. 

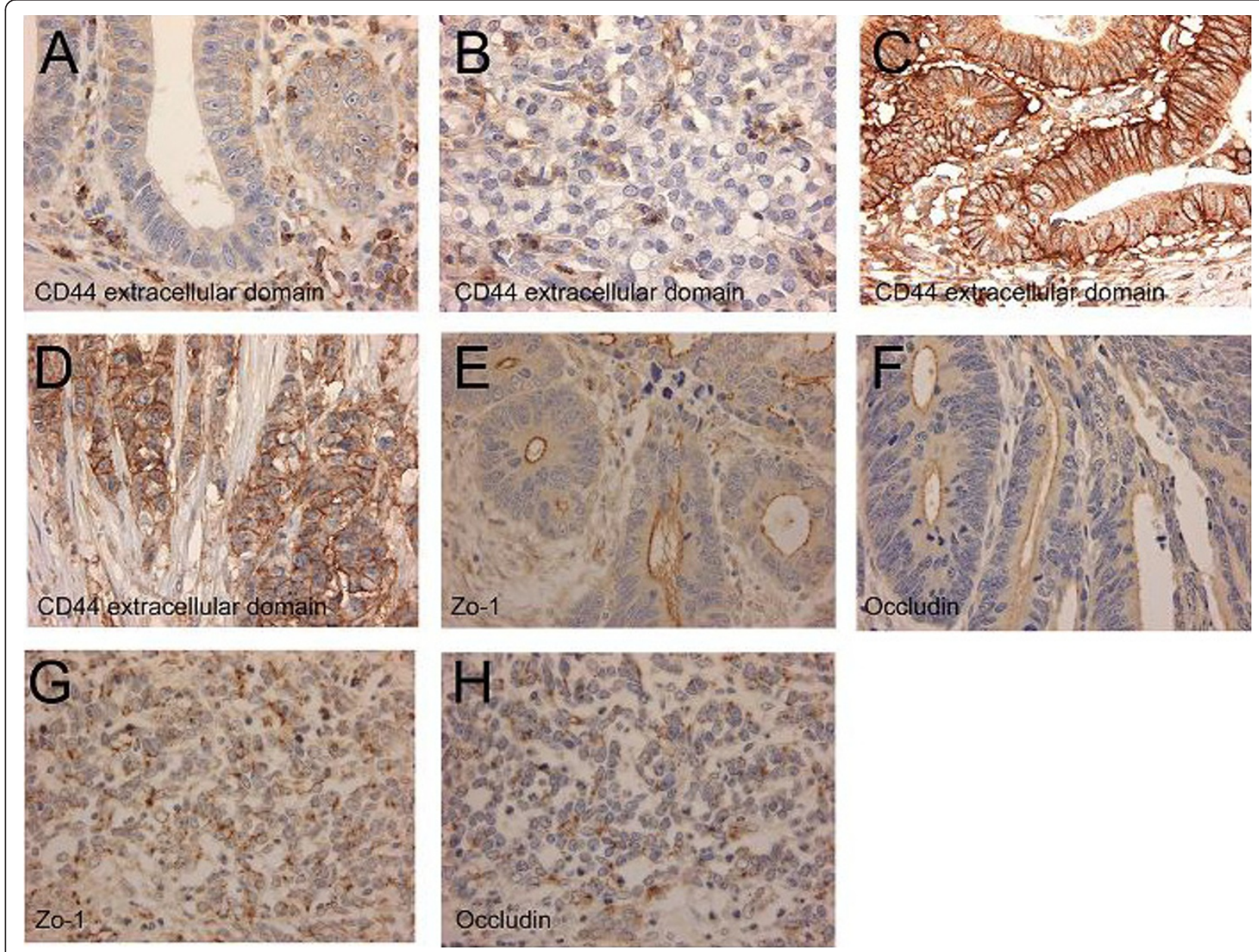

Figure 2 Representative photographs of CD44 extracellular domain, Zo-1, and occludin expression. CD44 extracellular domain is not expressed at the cell membrane of the invasive part of ulcerative colitis (UC)-associated well differentiated carcinoma (A) and a poorly differentiated carcinoma (B). On the other hand, in a case of sporadic well differentiated (C) and a case of sporadic poorly differentiated adenocarcinoma (D), membranous expression of CD44 extracellular domain is observed. Linear expression of Zo-1 (E) and occludin (F) is seen at the luminal surface in a case of UC-associated well differentiated carcinoma. However, in a UC-associated poorly differentiated case, dot-like expression of both Zo-1 (G) and occludin (H) is observed on the cell surface.

Table 4 Tumor differentiation and budding, and expression of CD44 extracellular domain, MMP-7, laminin-5 2 , and sialyl $L e^{X}$ in invasive fronts

\begin{tabular}{|c|c|c|c|c|c|c|}
\hline & $n$ & Tumor budding $(/ \mathrm{cm})$ & CD44 & MMP-7 & Laminin-5 $\gamma 2$ & Sialyl Le ${ }^{\mathrm{X}}$ \\
\hline \multicolumn{7}{|l|}{ Sporadic cancer } \\
\hline Well differentiated & 30 & $206.7 \pm 293.9$ & $5.5 \pm 2.8^{*}$ & $4.2 \pm 3.4$ & $5.2 \pm 2.7$ & $3.2 \pm 3.3$ \\
\hline Moderetely differentiated & 37 & $264.0 \pm 240.6$ & $5.1 \pm 2.6$ & $4.4 \pm 3.4$ & $5.7 \pm 2.7$ & $4.2 \pm 3.1$ \\
\hline Poorly differentiated & 8 & $395.8 \pm 280.5$ & $6.6 \pm 2.6^{* *}$ & $2.6 \pm 2.9$ & $4.6 \pm 3.5$ & $1.1 \pm 0.8$ \\
\hline \multicolumn{7}{|l|}{ UC-cancer } \\
\hline Well differentiated & 6 & $146.2 \pm 239.4$ & $2.2 \pm 1.5^{*}$ & $3.8 \pm 2.8$ & $4.0 \pm 2.6$ & $1.3 \pm 2.3$ \\
\hline Moderately differentiated & 4 & $157.0 \pm 178.7$ & $2.8 \pm 1.5$ & $4.7 \pm 1.5$ & $5.0 \pm 1.2$ & $1.0 \pm 0.0$ \\
\hline Poorly differentiated & 5 & $145.8 \pm 213.4$ & $1.2 \pm 1.6^{* *}$ & $1.0 \pm 1.0$ & $1.8 \pm 2.0$ & $1.4 \pm 1.5$ \\
\hline
\end{tabular}

MMP - matrix metalloproteinase; $n$ - number of cases; Le ${ }^{\mathrm{X}}$ - Lewis $\mathrm{X}$; UC - ulcerative colitis.

${ }^{*} P=0.010$.

** $P<0.001$. 


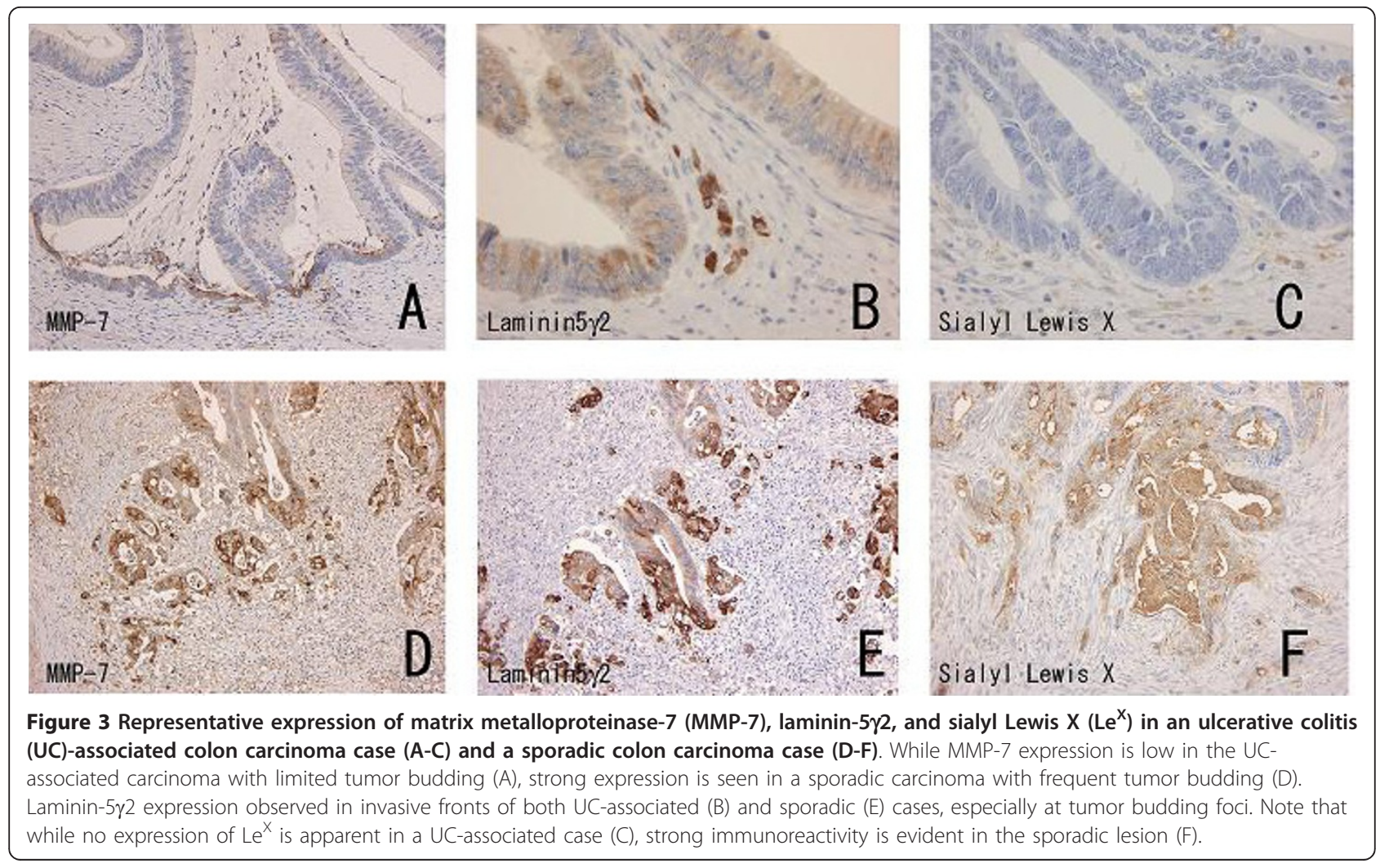

et al. [30] examined mutations with the PCR-single strand conformation polymorphism method while Mirabelli-Primdahl et al. [31] and Aust et al. [32] used PCRdirect sequencing. Although the frequency of beta-catenin mutations thus appears to vary, in the present study, nuclear expression did not show any positive relation with tumor budding, a morphological feature of invading carcinomas. We conclude that the role of betacatenin in invasion may be limited.

In our previous study, it was shown that expression of the CD44 standard form, variant 3, and variant 6 was reduced in UC-associated neoplasia compared to their sporadic counterparts [5]. In the present study, CD44 extracellular domain expression was significantly lower in UC-associated carcinoma than in its sporadic counterparts. Not the splicing variant but CD44 extracellular domain cleavage is considered to play a critical role in CD44-madiated tumor cell migration by regulating the

Table 5 Tumor budding in UC-associated and sporadic colon carcinomas

\begin{tabular}{lll}
\hline & $\boldsymbol{n}$ & Foci of tumor budding $(/ \mathbf{c m})$ \\
\hline Sporadic cancer, right & 34 & $278.4 \pm 316.1$ \\
Sporadic cancer, left & 41 & $235.9 \pm 225.9$ \\
UC cancer & 15 & $148.9 \pm 200.9$ \\
\hline
\end{tabular}

UC - ulcerative colitis; $n$ - number of cases. interaction between CD44 and extracellular matrix $[33,34]$. It may play a key role in invasion of UCassociated carcinoma and its loss may be related with poor prognosis. On the other hand, tight junction associated proteins showed no difference. Although lesions with poorer differentiation showed reduced expression (dot pattern) of Zo-1 and occludin, the barrier function of tight junction may be essential for epithelial cells including carcinoma to maintain the microenvironment.

The expression of both laminin-5 2 , a marker of basement membrane disruption, and sialyl $\mathrm{Le}^{\mathrm{X}}$, a cell surface antigen suggestive of a poor prognosis, showed here paradoxically lower tendency in UC-associated carcinomas than in sporadic counterparts. In invasion of UCassociated carcinoma, adhesion between CD44 molecule and extracellular matrix might be more important than basement membrane disruption or the alteration of sialyl Lewis antigens.

The average figures of tumor budding tended to be lower in UC-associated carcinomas than those in sporadic carcinomas, even in moderately to poorly differentiated groups. This may not be concordant with the findings that UC-associated carcinoma showed poorer differentiation in the submucosa or deeper parts. However, histologically, different from sporadic carcinomas, poorly differentiated UC-associated carcinoma cells often tended to show trabecular arrangement or much 
Table 6 Relation among beta-catenin expression and tumor budding

\begin{tabular}{|c|c|c|c|c|}
\hline & $n$ & $\begin{array}{l}\text { Foci of tumor budding } \\
(/ \mathrm{cm})\end{array}$ & $\begin{array}{l}\beta \text {-catenin expression } \\
\text { membranous }\end{array}$ & $\begin{array}{l}\beta \text {-catenin expression } \\
\text { cytoplasmic }\end{array}$ \\
\hline \multicolumn{5}{|l|}{ Sporadic cancer } \\
\hline $\begin{array}{l}\beta \text {-catenin nuclear expression } \\
\text { negative }\end{array}$ & 26 & $248.5 \pm 255.6$ & $5.8 \pm 2.8$ & $4.2 \pm 2.0^{*}$ \\
\hline $\begin{array}{l}\beta \text {-catenin nuclear expression } \\
\text { positive }\end{array}$ & 49 & $258.7 \pm 279.0$ & $4.9 \pm 2.9$ & $6.6 \pm 2.3^{*}$ \\
\hline \multicolumn{5}{|l|}{ UC cancer } \\
\hline $\begin{array}{l}\beta \text {-catenin nuclear expression } \\
\text { negative }\end{array}$ & 13 & $170.1 \pm 208.4$ & $5.2 \pm 3.8$ & $3.2 \pm 1.9$ \\
\hline $\begin{array}{l}\beta \text {-catenin nuclear expression } \\
\text { positive }\end{array}$ & 2 & $11.5 \pm 16.3$ & $3.0 \pm 0.0$ & $6.0 \pm 2.8$ \\
\hline
\end{tabular}

UC - ulcerative colitis; $n$ - number of cases.

* $P<0.001$.
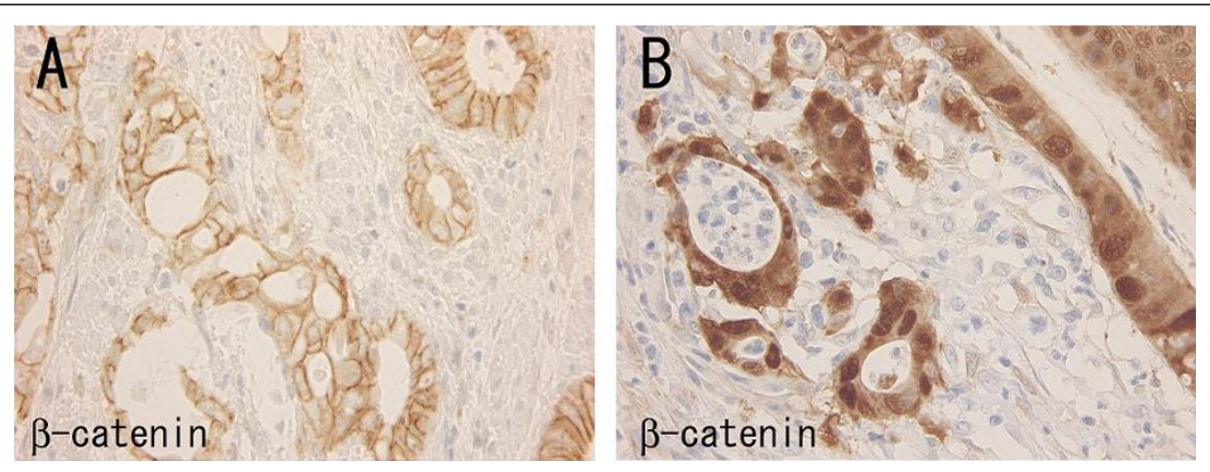

Figure 4 Expression of beta-catenin in a case of ulcerative colitis-associated carcinoma (A) and a case of sporadic colon carcinoma (B) Strong membranous expression is observed in the UC-associated carcinoma (A). Nuclear and cytoplasmic expression is seen in the sporadic colon carcinoma, instead of membranous expression (B).

mucous production, not showing so-called tumor budding. Therefore, this discordance may be related with characteristics of invasion of UC-associated carcinoma.

Because UC-associated carcinoma showed poorer differentiation when it invaded the submucosa or deeper layers, early detection of UC-associated neoplastic lesions before submucosal invasion is considered important. Recent advances in dye spraying and magnifying endoscopy for the colon have made it possible to detect early neoplastic lesions in UC follow-up patients $[35,36]$. Such endoscopic detection should allow great improvement in outcome for affected patients.

\section{Conclusions}

UC-associated carcinoma showed poorer differentiation when the carcinoma invaded submucosa or deeper, which might influence its poorer prognosis. Its invasive behavior is more associated with CD44 cleavage than with basement membrane disruption or sialyl Lewis antigen alteration.

\section{Acknowledgements}

This study was partly supported by a Grant-in-Aid from the Ministry of Education, Sports, Culture, Science, and Technology, Japan (\#19590364,
\#20590353), and from the Kanagawa Nanbyo Foundation. We thank Ms. Kiyomi Hana for her expert technical assistance. We also express our appreciation to Mr. Robert E. Brandt, CEO, MedEd Japan, for his careful reading and revision of the scientific English language in the manuscript.

\section{Authors' contributions}

TM carried out the experiments, collected and interpreted the data, and wrote the manuscript. YN carried out the molecular experiments, and KA performed immunohistochemical staining and evaluation. TY, MK, and NN analyzed the data. IO contributed conception and designed the study. All authors read and approved the final manuscript.

\section{Competing interests}

The authors declare that they have no competing interests.

Received: 25 November 2010 Accepted: 7 April 2011 Published: 7 April 2011

\section{References}

1. Eaden JA, Abrams KR, Mayberry JF: The risk of colorectal cancer in ulcerative colitis: a meta-analysis. Gut 2001, 48(4):526-535.

2. Connell WA, Talbot IC, Harpaz N, Britto N, Wilkinson KH, Kamm MA, Lennard-Jones JE: Clinicopathological characteristics of colorectal carcinoma complicating ulcerative colitis. Gut 1994, 35(10):1419-1423.

3. Hinton JM: Risk of malignant change in ulcerative colitis. Gut 1966, 7(5):427-432.

4. Lavery IC, Chiulli RA, Jagelman DG, Fazio WW, Weakley FL: Survival with carcinoma arising in mucosal ulcerative colitis. Ann Surg 1982, 195(4):508-512.

5. Mikami T, Mitomi H, Hara A, Yanagisawa N, Yoshida T, Tsuruta O, Okayasu I: Decreased expression of CD44, alpha-catenin, and deleted colon 
carcinoma and altered expression of beta-catenin in ulcerative colitisassociated dysplasia and carcinoma, as compared with sporadic colon neoplasms. Cancer 2000, 89(4):733-740.

6. Jass JR, Baker M, Fraser L, Walsh MD, Whitehall VL, Babrielli B, Young J, Leggett BA: APC mutation and tumour budding in colorectal cancer. $J$ Clin Pathol 2003, 56(1):69-73.

7. Ueno H, Murphy J, Jass JR, Mochizuki H, Talbot IC: Tumour "budding" as an index to estimate the potential of aggressiveness in rectal cancer. Histopathology 2002, 40(2):127-132.

8. Ogawa T, Yoshida T, Tsuruta T, Tokuyama W, Adachi S, Kikuchi M, Mikami T, Saigenji K, Okayasu I: Tumor budding is predictive of lymphatic involvement and lymph node metastasis in submucosal invasive colorectal adenocarcinomas and in non-polypoid compared with polypoid growth. Scand J Gastroenterol 2009, 44(5):605-614.

9. Ueno H, Mochizuki H, Hashiguchi Y, Shimazaki H, Aida S, Hase K, Matsukuma S, Kanai T, Kuruhara H, Ozawa K, Yoshimura K, Bekku S: Risk factors for an adverse outcome in early invasive colorectal carcinoma. Gastroenterology 2004, 127(2):385-394.

10. Gao AC, Lou W, Dong JT, Isaacs JT: CD44 is a metastasis suppressor gene for prostatic cancer located on human chromosome 11p13. Cancer Res 1997, 57(5):846-849.

11. Takamune Y, Ikebe T, Nagano O, Nakayama H, Ota K, Obayashi T, Saya H, Shinohara M: ADAM-17 associated with CD44 cleavage and metastasis in oral squamous cell carcinoma. Virchows Arch 2007, 450(2):169-177.

12. Okamoto I, Tsuiki H, Kenyon LC, Godwin AK, Emlet DR, Hogado-Madruga M, Lanham IS, Joynes CJ, Vo KT, Guha A, Matsumoto M, Ushio Y, Saya H, Wong AJ: Proteolytic cleavage of the CD44 adhesion molecule in multiple human tumors. Am J Pathol 2002, 160(2):441-447.

13. Kimura $Y$, Shiozaki H, Hirao M, Maeno Y, Doki Y, Inoue M, Monden T, AndoAkatsuka Y, Furuse M, Tsukita S, Monden M: Expression of occludin, tightjunction-associated protein, in human digestive tract. Am J Pathol 1997, 151(1):45-54.

14. Cadigan KM, Liu Yl: Wnt signaling: complexity at the surface. J Cell Science 2006, 119(Pt3):395-402.

15. Doucas H, Garcea G, Neal CP, Manson MM, Berry DP: Changes in the Wnt signaling pathway in gastrointestinal cancers and their prognostic significance. Eur J Cancer 2005, 41(3):365-379.

16. Ii $M$, Yamamoto $H$, Adachi $Y$, Maruyama $Y$, Shinomura $Y$ : Role of matrix metalloproteinase-7 (matrilysin) in human cancer invasion, apoptosis, growth, and angiogenesis. Exp Biol Med 2006, 231(1):20-27.

17. Remy L, Trespeuch C, Bachy S, Scoazec JY, Rouselle P: Matrilysin 1 influences colon carcinoma cell migration by cleavage of the laminin- 5 beta3 chain. Cancer Res 2006, 66(23):11228-11237.

18. Pirilä E, Sharabi A, Salo T, Quaranta V, Tu H, Heljasvaara R, Koshikawa N, Sorsa T, Maisi P: Matrix metalloproteinases process the laminin-5 52 -chain and regulate epithelial cell migration. Biochem Biophys Res Commun 2003, 303(4):1012-1017.

19. Irimura T, Matsushita Y, Hoff SD, Yamori T, Nakamori S, Frazier ML, Giacco GG, Cleary KR, Ota DM: Ectopic expression of mucins in colorectal cancer metastasis. Semin Cancer Biol 1991, 2(2):129-139.

20. Matsushita Y, Cleary KR, Ota DM, Hoff SD, Irimura T: Sialyl-dimeric Lewis-X antigen expressed on mucin-like glycoproteins in colorectal cancer metastasis. Lab Invest 1990, 63(6):780-791.

21. Izawa M, Kumamoto K, Mitusoka C, Kanamori A, Ohmori K, Ishida H, Nakamura S, Kurata-Miura K, Sasaki K, Nishi T, Kannagi R: Expression of sialyl 6-sulfo Lewis $x$ is inversely correlated with conventional sialyl Lewis $\times$ expression in human colorectal cancer. Cancer Res 2000, 60(5):1410-1416.

22. Izumi Y, Taniuchi Y, Tsuji T, Smith CW, Nakamori S, Fidler IJ, Irimura T: Characterization of human colon carcinoma variant cells selected for sialyl Le ${ }^{\mathrm{X}}$ carbohydrate antigen: liver colonization and adhesion to vascular endothelial cells. Exp Cell Res 1995, 216(1):215-221.

23. Nakamori S, Kameyama M, Imaoka S, Furukawa H, Ishikawa O, Sasaki Y, Kabuto T, Iwanaga T, Matsushita Y, Irimura T: Increased expression of sialyl Lewis ${ }^{\mathrm{x}}$ antigen correlates with poor survival in patients with colorectal carcinoma: clinicopathological and immunohistochemical study. Cancer Res 1993, 53(15):3632-3637.

24. Nakamori S, Kameyama M, Imaoka S, Furukawa H, Ishikawa O, Sasaki Y, Izumi Y, Irimura T: Involvement of carbohydrate antigen sialyl Lewis ${ }^{\mathrm{x}}$ in colorectal cancer metastasis. Dis Colon Rectum 1997, 40(4):420-431.
25. Riddell RH, Goldman H, Ranshoff DF, Appelman HD, Fenoglio CM, Haggitt RC, Ahren C, Correa P, Hamilton SR, Morson BC, Sommers SC, Yardley $\mathrm{JH}$ : Dysplasia in inflammatory bowel disease: standardized classification with provisional clinical application. Hum Pathol 1983, 14(11):931-968.

26. Hamilton SR, Aaltonen LA: World Health Organization. Classification of Tumours: Pathology and Genetics of Tumours of the Digestive System Lyon, International Agency for Research on Cancer (IARC) Publications; 2001.

27. Sinicrope FA, Ruan SB, Clearly KR, Stephens LC, Lee JJ, Levin B: bcl-2 and p53 oncoprotein expression during colorectal tumorigenesis. Cancer Res 1995, 55(2):237-241.

28. Feng Han Q, Zhao W, Bentel J, Shearwood AM, Zeps N, Joseph D, lacopetta B, Dharmarajan A: Expression of sFRP-4 and beta-catenin in human colorectal carcinoma. Cancer Lett 2006, 231(1):129-137.

29. Saegusa M, Hashimura M, Yoshida T, Okayasu I: Beta-catenin mutations and aberrant nuclear expression during endometrial tumorigenesis. $\mathrm{Br} J$ Cancer 2001, 84(2):209-217.

30. Garinis GA, Spanakis NE, Menounos PG, Manolis EN, Peros G: Transcriptional impairment of beta-catenin/E-cadherin complex is not associated with beta-catenin mutations in colorectal carcinomas. $\mathrm{Br} J$ Cancer 2003, 88(2):206-209.

31. Mirabelli-Primdahl L, Gryfe R, Kim H, Millar A, Luceri C, Dale D, Holowaty E, Bapat B, Gallinger S, Redston M: Beta-catenin mutations are specific for colorectal carcinomas with microsatellite instability but occur in endometrial carcinomas irrespective of mutator pathway. Cancer Res 1999, 59(14):3346-3351.

32. Aust DE, Terdiman JP, Willenbucher RF, Chang CG, Molinaro-Clark A, Baretton GB, Loehrs U, Waldman FM: The APC/beta-catenin pathway in ulcerative colitis-associated colorectal carcinomas. Cancer 2002, 94(5):1421-1427.

33. Kajita M, Itoh $Y$, Chiba T, Mori H, Okada A, Kinoh H, Seiki M: Membrane type 1 matrix metalloproteinase cleaves CD44 and promotes cell migration. J Cell Biol 2001, 153(5):893-904.

34. Okamoto I, Kawano Y, Tsuiki H, Sasaki J, Nakao M, Matsumoto M, Suga M, Ando M, Nakajima M, Saya H: CD44 cleavage induced by a membraneassociated metalloprotease plays a critical role in tumor cell migration. Oncogene 1999, 18(7):1435-1446.

35. Matsumoto $\mathrm{T}$, Iwao $\mathrm{Y}$, Igarashi M, Watanabe $\mathrm{K}$, Otsuka $\mathrm{K}$, Watanabe $\mathrm{T}$, lizuka B, Hida N, Sada M, Chiba T, Kudo S, Oshitani N, Nagawa H, Ajioka Y, Hibi T: Endoscopic and chromoendoscopic atlas featuring dysplastic lesions in surveillance colonoscopy for patients with long-standing ulcerative colitis. Inflamm Bowel Dis 2008, 14(2):259-264.

36. Sada M, Igarashi M, Yoshizawa S, Kobayashi K, Katsumata T, Saigenji K, Otani Y, Okayasu I, Mitomi H: Dye spraying and magnifying endoscopy for dysplasia and cancer surveillance in ulcerative colitis. Dis Colon Rectum 2004, 47(11):1816-1823.

doi:10.1186/1746-1596-6-30

Cite this article as: Mikami et al:: Invasive behavior of ulcerative colitisassociated carcinoma is related to reduced expression of CD44 extracellular domain: comparison with sporadic colon carcinoma. Diagnostic Pathology 2011 6:30.

\section{Submit your next manuscript to BioMed Central and take full advantage of:}

- Convenient online submission

- Thorough peer review

- No space constraints or color figure charges

- Immediate publication on acceptance

- Inclusion in PubMed, CAS, Scopus and Google Scholar

- Research which is freely available for redistribution

Submit your manuscript at www.biomedcentral.com/submit
C Biomed Central 